\title{
Fuzzy Comprehensive Risk Assessment Method Based on Consistent Ma- trix and Information Entropy
}

\author{
Peng Jianfen ${ }^{1, *}$ and Liu Heng ${ }^{1,2}$ \\ ${ }^{1}$ China Electronics Cyberspace Great Wall Applications Ltd., Beijing 100191, China \\ ${ }^{2}$ Institute of Computing Technology Chinese Academy of Sciences, Beijing, China
}

\begin{abstract}
To solve the following problems of information security risk assessment method: inconsistency of judgment matrix, and irrationality of expert weight, risk assessment method based on the consistent matrix and information entropy (RAMCI) is proposed, which uses the priority relationship matrix to establish consistent judgment matrix and information entropy to calculate the weight of multiple experts with an indicator score. This method was used in a case to assess the risk. The results show that: in comparison with previous assessment methods, RAMCI has the following advantages: consistency of judgment matrix not concerned; objectively reflects the statistical profile of individual risk factors. So RAMCI is a practical information system risk assessment method.
\end{abstract}

Keywords: Fuzzy comprehensive risk assessment, Information entropy, Consistent matrix.

\section{INTRODUCTION}

Information systems security has been greatly concerned because of the development and application of IT, the risk assessment is an important part of information system security engineering, and it is also basis and premise of establishing the system of information system security [1]. The existing risk assessment methods are classified into three main categories: the qualitative, the quantitative, and the mixed methods, in which quantitative and qualitative methods are combined. The mixed methods make up for subjectivity of the qualitative assessment method and simplicity of the quantitative assessment [2].

The Analytic Hierarchy Process (AHP) is a decisionmaking method combining quantitative and qualitative analysis [3], the method will make the risk factors of decision-making into target, rule, scheme and etc; and based on which, carry out decision-making method of quantitative and qualitative analysis. The risk factor weight of information security risk assessment is traditionally scored by expert; there is a lot of fuzziness in the expert evaluation. Therefore, fuzzy comprehensive evaluation method carries out quantitative treatment when comprehensive evaluation of the system is required. Nowadays the fuzzy comprehensive risk assessment methods based on AHP [4,5] were appeared, which used membership degree of fuzzy mathematics to quantify the assessment factors, and make an overall evaluation of the things or objects restricted by many factors. So it can solve a variety of non-deterministic problems which are fuzzy and difficult to quantify [6].

*Address correspondence to this author at the China Electronics Cyberspace Great Wall Applications Ltd., Beijing 100191, China, Tel: 86-10-82092800; Fax; 86-10-82092724; E-mail: horsepjf@gmail.com
Fuzzy comprehensive evaluation method based on AHP needs to construct the judgment matrix; the consistency tests of each judgment matrix are needed. If matrix does not meet consistency criteria, then the judgment matrix needs to be modified until the matrix meets consistency criteria. Characteristic root and the corresponding eigenvectors of matrix are computed during consistency tests of matrix, which is relatively time-consuming. On the other hand, expert weight needs to be calculated. If the value of weights is equal, it cannot reflect the level of expertise.

In order to solve the inconsistency of the judgment matrix and irrationality of expert weight, fuzzy comprehensive risk assessment method based on consistent matrix and information entropy (RAMCI) is proposed.

\section{RELATE KNOWLEDGE}

\subsection{Fuzzy Consistent Matrix and Configuration}

Assumed risk factor set $B=\left\{A_{1}, A_{2}, \cdots, A_{n}\right\}$,if $0 \leq a_{i j} \leq 1$ for $\forall i, j=1,2,3, \cdots, n$, then $A=\left(a_{i j}\right)_{n \times n}$ is called a fuzzy complementary matrix, where $a_{i j}$ is the preference degree of $A_{i}$ to $A_{j}$.

$$
a_{i j}=\left\{\begin{array}{l}
0 \quad A_{i} \text { is strictly inf er to } A_{j} \\
(0,0.5) A_{i} \text { is inf er to } A_{j} \\
0.5 \quad A_{i} \text { is identical to } A_{j} \\
(0.5,1) A_{i} \text { is sup perior to } A_{j} \\
1 \quad A_{i} \text { is strictly sup perior to } A_{j}
\end{array}\right.
$$


Definition 1 If the fuzzy complementary matrix $A=\left(a_{i j}\right)_{n \times n}$ is satisfied:

$\forall i, j, k=1,2, \ldots, n, \quad a_{i j}=a_{i k}-a_{j k}+0.5$

Then the fuzzy complementary matrix $A=\left(a_{i j}\right)_{n \times n}$ is fuzzy consistent matrix [7].

The following preference of comparison is carried out between any two of the risk factors; a priority relation matrix $F=\left(f_{i j}\right)_{n \times n}$ is established.

$f_{i j}=\left\{\begin{array}{l}0 \quad A_{i} \text { is inf er to } A_{j} \\ 0.5 \quad A_{i} \text { is identical to } A_{j} \\ 1 \quad A_{i} \text { is sup perior to } A_{j}\end{array}\right.$

Suppose $F=\left(f_{i j}\right)_{n \times n}$ as a priority relation matrix, the matrix $R=\left(r_{i j}\right)_{n \times n}$ is consistency of fuzzy complementary judgment matrix [8], where

$r_{i}=\sum_{j=1}^{n} f_{i j}, i=1,2,3, \cdots, n$

$r_{i j}=\frac{r_{i}-r_{j}}{2 n}+0.5$

\subsection{Information Entropy}

The concept of information entropy was put forward by the Shannon [9] in "A Mathematical Theory of Communication "published in 1948. Information entropy is the measure of uncertainty of the random variable and defined as follows:

Definition 2: Discrete random variable $X$ with possible values $s_{1}, s_{2}, \cdots, s_{n}$ and probability mass function $P\left(s=s_{i}\right)=p_{i}$,

$H(X)=-C \sum_{i=1}^{n} p_{i} \log p_{i}$

Where $0 \leq p_{i} \leq 1$, and $\sum_{i=1}^{n} p_{i}=1$.

when $p_{1}=p_{2}=\cdots=p_{n}=\frac{1}{n}$, the information entropy achieves the max value $C \log n[10]$.

The fuzzy comprehensive risk assessment method needs a lot of expertise to get fuzzy assessment of risk factor, each level of expertise is not the same, and expert weight also needs to be calculated. Large gap usually occurs among the result of risk factor assessment. In order to ensure the consistency of the results of the expert assessment, expert weight needs be calculated.

The higher the level of expertise, the larger becomes the gap among the result of risk factor assessment. High level of expertise should play more important role in the comprehensive evaluation than low level of expertise; information entropy can reflect the degree of dispersion of the indicator support. The coefficient of weight can be calculated as follows:

If matrix $A_{n \times m}$ denotes $n$ experts, $m$ level of on an indicator is assessed:

$A=\left[\begin{array}{cccc}a_{11} & a_{12} & \cdots & a_{1 m} \\ a_{21} & a_{22} & \cdots & a_{2 n} \\ \vdots & & \cdots & \vdots \\ a_{n 1} & a_{n 2} & \cdots & a_{n m}\end{array}\right]$

Then the coefficient of weight is

$\alpha_{i}=\left(1-e_{i}\right) /\left(n-\sum_{i=1}^{n} e_{i}\right) \quad$ where, $e_{i}=-\frac{1}{\log m} \sum_{j=1}^{m} a_{i j} \log a_{i j}$, $\sum_{i=1}^{n} \alpha_{i}=1, \quad 0 \leq \alpha_{i} \leq 1$

\section{RAMCI}

In the risk assessment process, using the priority relations matrix of the risk factor to establish a consistent judgment matrix, consistency test of conventional judgment matrix is eliminated. At the same time the use of information entropy to calculate the weight of the review's score makes the score results of the expert more reasonable. Therefore, RAMCI carries out the following steps.

(1) Carries out the decomposition of the system using AHP, constructing a hierarchical model.

(2) Establishes priority relation matrix in accordance with equation (1), the priority relation matrix is transformed to a consistent matrix according to equation (2) and (3) sort.

(3) Calculates the total weight of each risk factor and

(4) According to the system, determines the evaluation set.

(5) Uses information entropy to calculate the degree of membership of the each risk factor relative to evaluation set. tion.

(6) Calculates the result of fuzzy comprehensive evalua-

The details of the process are shown in Fig. (1).

\section{CASE STUDY}

\subsection{Case Computation}

\subsubsection{Construction of a Hierarchical Model}

A hierarchical model is built in Fig. (2) [11].

\subsubsection{Configuration of Priority Relation and Correspond- ing Fuzzy Consistent Matrix}

A priority relation matrix and corresponding fuzzy consistent matrix are shown in Table $\mathbf{1 - 5}$, the priority relation matrix is transformed into fuzzy consistent matrix according to equation (2) and (3). 


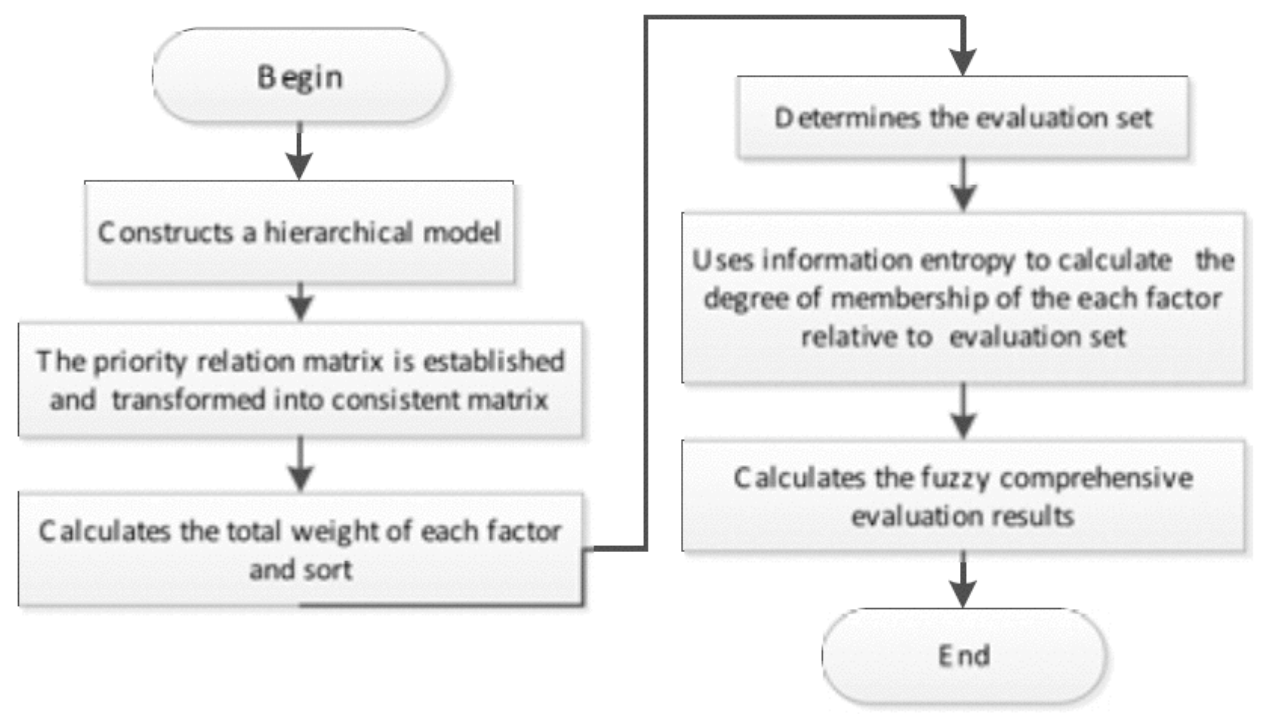

Fig. (1). Flow chart of RAMCI.

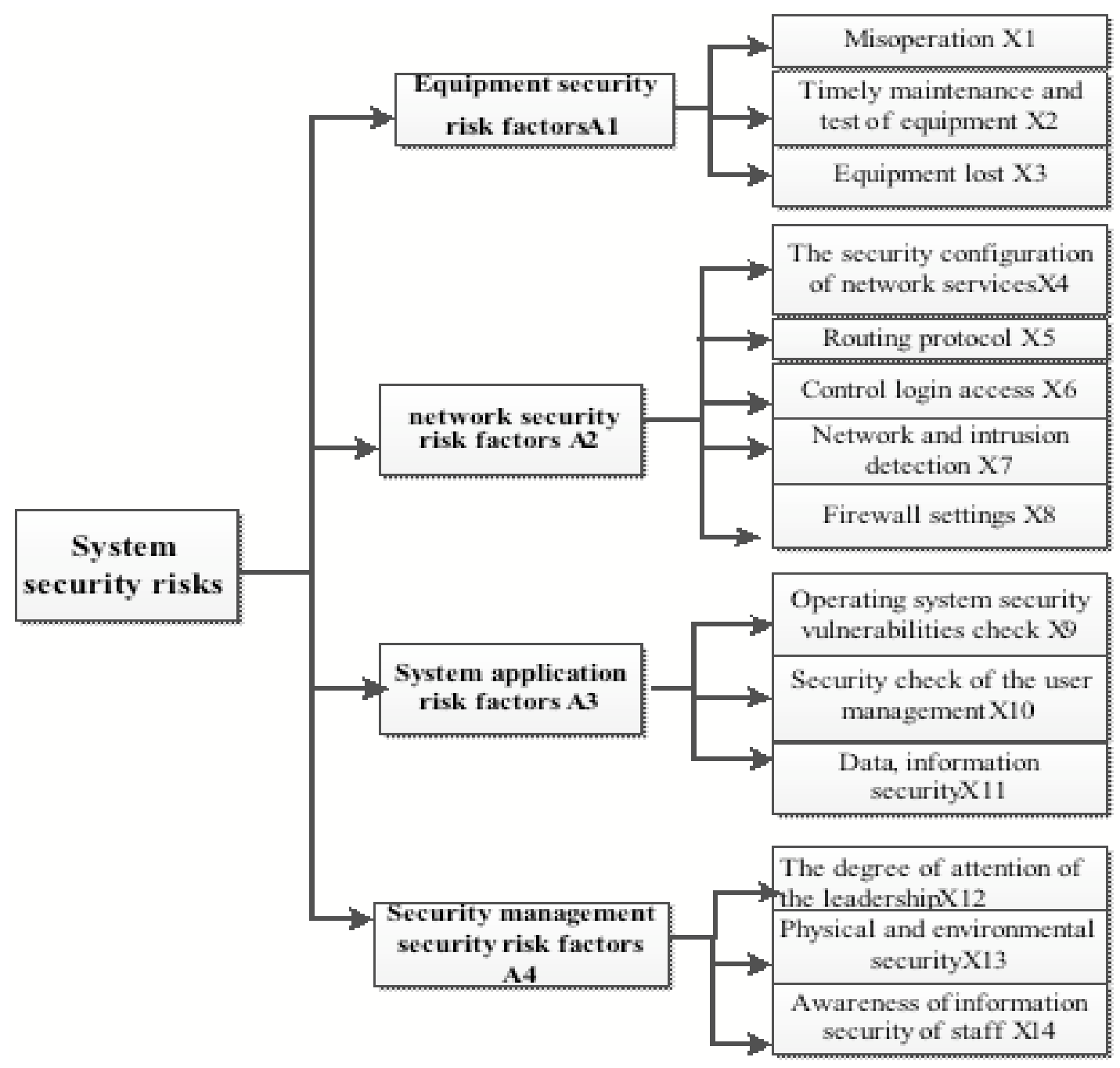

Fig. (2). Hierarchical model. 
Table 1. A Priority Relation Matrix (a) and Corresponding Fuzzy Consistent Matrix (b) in Target level

\begin{tabular}{|c|c|c|c|c|}
\hline Target Level & A1 & A2 & A3 & A4 \\
\hline \hline A1 & 0.5 & 0 & 0 & 0 \\
\hline A2 & 1.0 & 0.5 & 1.0 & 1.0 \\
\hline A3 & 1.0 & 0 & 0.5 & 1 \\
\hline A4 & 1.0 & 0 & 0 & 0.5 \\
\hline
\end{tabular}

(a)

\begin{tabular}{|c|c|c|c|c|}
\hline Target Level & A1 & A2 & A3 & A4 \\
\hline \hline A1 & 0.5 & $1 / 8$ & 0.25 & $3 / 8$ \\
\hline A2 & $7 / 8$ & 0.5 & $5 / 8$ & 0.75 \\
\hline A3 & 0.75 & $3 / 8$ & 0.5 & $5 / 8$ \\
\hline A4 & $5 / 8$ & 0.25 & $3 / 8$ & 0.5 \\
\hline
\end{tabular}

(b)

Table 2. A Priority Relation Matrix (a) and Corresponding Fuzzy Consistent Matrix (b) in A1 Level

\begin{tabular}{|c|c|c|c|}
\hline $\mathbf{A 1}$ & $\mathbf{X 1}$ & $\mathbf{X 2}$ & $\mathbf{X 3}$ \\
\hline \hline $\mathbf{X 1}$ & 0.5 & 0 & 1 \\
\hline $\mathbf{X 2}$ & 1 & 0.5 & 1 \\
\hline $\mathbf{X 3}$ & 0 & 0 & 0.5 \\
\hline
\end{tabular}

(a)

\begin{tabular}{|c|c|c|c|}
\hline $\mathbf{A 1}$ & $\mathbf{X 1}$ & $\mathbf{X 2}$ & $\mathbf{X 3}$ \\
\hline \hline $\mathbf{X 1}$ & 0.5 & 0.333 & 0.667 \\
\hline $\mathbf{X 2}$ & 0.667 & 0.5 & 0.833 \\
\hline $\mathbf{X 3}$ & 0.333 & 0.167 & 0.5 \\
\hline
\end{tabular}

(b)

Table 3. A Priority Relation Matrix (a) and Corresponding Fuzzy Consistent Matrix (b) in A2 Level

\begin{tabular}{|c|c|c|c|c|c|}
\hline $\mathbf{A 2}$ & $\mathbf{X 4}$ & $\mathbf{X 5}$ & $\mathbf{X 6}$ & $\mathbf{X 7}$ & $\mathbf{X 8}$ \\
\hline \hline $\mathbf{X 4}$ & 0.5 & 0 & 1.0 & 0 & 0 \\
\hline $\mathbf{X 5}$ & 1.0 & 0.5 & 0 & 1 & 1 \\
\hline $\mathbf{X 6}$ & 0 & 1 & 0.5 & 1 & 0 \\
\hline $\mathbf{X 7}$ & 1 & 0 & 0 & 0.5 & 0 \\
\hline $\mathbf{X 8}$ & 1 & 0 & 1 & 1 & 0.5 \\
\hline
\end{tabular}

(a)

\begin{tabular}{|c|c|c|c|c|c|}
\hline $\mathbf{A 2}$ & $\mathbf{X 4}$ & $\mathbf{X 5}$ & $\mathbf{X 6}$ & $\mathbf{X 7}$ & $\mathbf{X 8}$ \\
\hline \hline $\mathbf{X 4}$ & 0.5 & 0.3 & 0.4 & 0.5 & 0.3 \\
\hline $\mathbf{X 5}$ & 0.7 & 0.5 & 0.6 & 0.7 & 0.5 \\
\hline $\mathbf{X 6}$ & 0.6 & 0.4 & 0.5 & 0.6 & 0.4 \\
\hline $\mathbf{X 7}$ & 0.5 & 0.3 & 0.4 & 0.5 & 0.3 \\
\hline $\mathbf{X 8}$ & 0.7 & 0.5 & 0.6 & 0.7 & 0.5 \\
\hline
\end{tabular}

(b)

Table 4. A priority Relation Matrix (a) and Corresponding Fuzzy Consistent Matrix (b) in A3 Level

\begin{tabular}{|c|c|c|c|}
\hline $\mathbf{A 3}$ & $\mathbf{X 9}$ & $\mathbf{X 1 0}$ & $\mathbf{X 1 1}$ \\
\hline \hline $\mathbf{X 9}$ & 0.5 & 0 & 0.5 \\
\hline $\mathbf{X 1 0}$ & 1 & 0.5 & 1 \\
\hline $\mathbf{X 1 1}$ & 0.5 & 0 & 0.5 \\
\hline
\end{tabular}

(a)

\begin{tabular}{|c|c|c|c|}
\hline $\mathbf{A 3}$ & $\mathbf{X 9}$ & $\mathbf{X 1 0}$ & $\mathbf{X 1 1}$ \\
\hline \hline $\mathbf{X 9}$ & 0.5 & 0.25 & 0.5 \\
\hline $\mathbf{X 1 0}$ & 0.75 & 0.5 & 0.75 \\
\hline $\mathbf{X 1 1}$ & 0.5 & 0.25 & 0.5 \\
\hline
\end{tabular}

(b)

Table 5. A priority Relation Matrix (a) and Corresponding Fuzzy Consistent Matrix (b) in A4 Level

\begin{tabular}{|c|c|c|c|}
\hline $\mathbf{A 4}$ & $\mathbf{X 1 2}$ & $\mathbf{X 1 3}$ & $\mathbf{X 1 4}$ \\
\hline \hline $\mathbf{X 1 2}$ & 0.5 & 0.5 & 0 \\
\hline $\mathbf{X 1 3}$ & 0.5 & 0.5 & 0 \\
\hline $\mathbf{X 1 4}$ & 1 & 1 & 0.5 \\
\hline
\end{tabular}

(a)

\begin{tabular}{|c|c|c|c|}
\hline $\mathbf{A 4}$ & $\mathbf{X 1 2}$ & $\mathbf{X 1 3}$ & $\mathbf{X 1 4}$ \\
\hline \hline $\mathbf{X 1 2}$ & 0.5 & 0.5 & 0.25 \\
\hline $\mathbf{X 1 3}$ & 0.5 & 0.5 & 0.25 \\
\hline $\mathbf{X 1 4}$ & 0.75 & 0.75 & 0.5 \\
\hline
\end{tabular}

(b) 
Table 6. The Weight of Risk Factor

\begin{tabular}{|c|c|c|c|c|c|c|}
\hline Weight & Factor & A1 & A2 & $\mathbf{A 3}$ & A4 & Weight \\
\hline \multirow{3}{*}{0.1478} & 1 & 0.3333 & & & & 0.0493 \\
\hline & 2 & 0.4537 & & & & 0.0671 \\
\hline & 3 & 0.2130 & & & & 0.0315 \\
\hline \multirow{3}{*}{0.3522} & 4 & & 0.1587 & & & 0.0559 \\
\hline & 7 & & 0.1587 & & & 0.0559 \\
\hline & 8 & & 0.2413 & & & 0.085 \\
\hline \multirow[b]{2}{*}{0.2841} & 9 & & & 0.2738 & & 0.0778 \\
\hline & 10 & & & 0.4524 & & 0.1285 \\
\hline 0.2159 & 14 & & & & 0.4524 & 0.0977 \\
\hline
\end{tabular}

"Positive law" deals with the value; the first column of fuzzy consistent matrix is normalized in Table $\mathbf{1}$ as an example.

$$
\begin{aligned}
& \sum_{k=1}^{4} a_{k 1}=0.5+0.875+0.75+0.625=2.75 \\
& \overline{a_{11}}=\frac{a_{11}}{\sum_{k=1}^{4} a_{k 1}}=\frac{0.5}{2.75}=0.1818 \\
& \overline{a_{21}}=\frac{a_{21}}{\sum_{k=1}^{4} a_{k 1}}=\frac{0.875}{2.75}=0.3182 \\
& \overline{a_{31}}=\frac{a_{31}}{\sum_{k=1}^{4} a_{k 1}}=\frac{0.75}{2.75}=0.2727 \quad \frac{a_{41}}{a_{41}}=\frac{0.625}{\sum_{k=1}^{4} a_{k 1}}=0.2273
\end{aligned}
$$

The remaining three columns are calculated on the same principle; the normalized judgment matrix is as follows.

$\left[\begin{array}{llll}0.1818 & 0.1 & 0.1428 & 0.1667 \\ 0.3182 & 0.4 & 0.3572 & 0.3333 \\ 0.2727 & 0.3 & 0.2857 & 0.2778 \\ 0.2273 & 0.2 & 0.2143 & 0.2222\end{array}\right]$

Judgment matrix is normalized in term of row:

$\overline{w_{1}}=\sum_{j=1}^{4} \overline{a_{1 j}}=0.1818+0.100+0.1428+0.1667=0.5913$

$\overline{w_{2}}=\sum_{j=1}^{4} \overline{a_{2 j}}=0.3182+0.400+0.3572+0.3333=1.4087$ $\overline{w_{3}}=\sum_{j=1}^{4} \overline{a_{3 j}}=0.2727+0.300+0.2857+0.2778=1.1362$

$\overline{w_{4}}=\sum_{j=1}^{4} \overline{a_{4 j}}=0.2273+0.200+0.2143+0.2222=0.8638$

Vector $\overline{w_{i}}$ is normalized to eigenvectors $w=[0.1478,0.3522,0.2841,0.2159]^{T}, \quad w$ is weigh of four risk factors.

Fuzzy consistent matrix is constructed according to the conformance requirements matrix, so the matrix itself conforms to the consistency and does not require consistency test. Other weights are as follow.

$$
\begin{aligned}
& w_{A_{1}}=[0.3333,0.4537,0.213]^{T} \\
& w_{A_{2}}=[0.1587,0.2413,0.200,0.1587,0.2413]^{T} \\
& w_{A_{3}}=[0.2738,0.4524,0.2738]^{T} \\
& w_{A_{4}}=[0.2738,0.2738,0.4524]^{T}
\end{aligned}
$$

\subsubsection{Level Sorting and Consistency Test}

The weight of risk factor is listed as Table $\mathbf{6}$.

The weight of first level of risk factor $w=[0.1478,0.3522,0.2841,0.2159]^{T}$

The weight of second level of risk factor:

$$
\begin{aligned}
& w_{A_{1}}=[0.3333,0.4537,0.2130]^{T} \\
& w_{A_{2}}=[0.1587,0.2413,0.200,0.1587,0.2413]^{T}
\end{aligned}
$$


Table 7. System Security Score Sheet

\begin{tabular}{|c|c|c|c|c|}
\hline Worse(W) & Bad(B) & General(G) & Good(GD) & Better(BE) \\
\hline \hline 5 & 4 & 3 & 2 & 1 \\
\hline
\end{tabular}

Table 8. Specialist Score and Membership of Factor X1

\begin{tabular}{|c|c|c|c|c|c|}
\hline & W & B & G & GD & 0.1 \\
\hline \hline s1 & 0.1 & 0.25 & 0.5 & 0.2 & 0.05 \\
\hline s2 & 0.2 & 0.2 & 0.2 & 0.3 & 0.2 \\
\hline s3 & 0.1 & 0.1 & 0.4 & 0.4 & 0.2 \\
\hline s4 & 0.05 & 0.2 & 0.3 & 0.2501 & 0.2 \\
\hline s5 & 0.1 & 0.2 & 0.3992 & 0.240 & 0.0715 \\
\hline M2 & 0.0839 & 0.1953 & 0.34 & 0.12 \\
\hline
\end{tabular}

Table 9. Specialist Score and Membership of Risk Factor X2

\begin{tabular}{|c|c|c|c|c|c|}
\hline & W & B & G & GD & 0.2 \\
\hline \hline s1 & 0.3 & 0.1 & 0.2 & 0.2 & 0.2 \\
\hline s2 & 0.1 & 0.4 & 0.2 & 0.2 & 0.1 \\
\hline s3 & 0.2 & 0.1 & 0.2 & 0.3 & 0.15 \\
\hline s4 & 0.25 & 0.1 & 0.3 & 0.2180 & 0.2 \\
\hline s5 & 0.1 & 0.2 & 0.2145 & 0.22 & 0.1671 \\
\hline M1 & 0.1706 & 0.2299 & 0.22 & 0.19 \\
\hline
\end{tabular}

Table 10. Specialist Score and Membership of Risk Factor X3

\begin{tabular}{|c|c|c|c|c|c|}
\hline & W & B & G & GD & 0.2 \\
\hline \hline s1 & 0.3 & 0.25 & 0.2 & 0.2 & 0.05 \\
\hline s2 & 0.4 & 0.2 & 0.1 & 0.25 & 0.1 \\
\hline s3 & 0.35 & 0.1 & 0.2 & 0.3 & 0.1 \\
\hline s4 & 0.05 & 0.2 & 0.3 & 0.25 & 0.25 \\
\hline s5 & 0.1 & 0.2 & 0.1985 & 0.24 & 0.1140 \\
\hline M1 & 0.2594 & 0.1889 & 0.2 & 0.13 \\
\hline M2 & 0.24 & 0.19 & & 0.24 \\
\hline
\end{tabular}


Table 11. Specialist Score and Membership of Risk Factor X4

\begin{tabular}{|c|c|c|c|c|c|}
\hline & W & B & G & GD & 0.3 \\
\hline \hline s1 & 0.2 & 0.25 & 0.2 & 0.25 & 0.05 \\
\hline s2 & 0.2 & 0.2 & 0.2 & 0.1 & 0.15 \\
\hline s3 & 0.1 & 0.3 & 0.4 & 0.15 & 0.1 \\
\hline s4 & 0.2 & 0.2 & 0.3 & 0.1764 & 0.1 \\
\hline s5 & 0.1 & 0.2 & 0.3176 & 0.20 \\
\hline M1 & 0.1391 & 0.2614 & 0.28 & 0.13 \\
\hline
\end{tabular}

Table 12. Specialist Score and Membership of Risk Factor X5

\begin{tabular}{|c|c|c|c|c|c|}
\hline & W & B & G & GD & 0.1 \\
\hline \hline s1 & 0.6 & 0.15 & 0.05 & 0.05 & 0.1 \\
\hline s2 & 0.5 & 0.2 & 0.2 & 0.1 & 0.15 \\
\hline s3 & 0.55 & 0.05 & 0.2 & 0.1 & 0.15 \\
\hline s4 & 0.4 & 0.2 & 0.1 & 0.1 \\
\hline M1 & 0.3 & 0.2 & 0.1371 & 0.0963 & 0.0963 \\
\hline M2 & 0.5285 & 0.1419 & 0.13 & 0.12 & 0.12 \\
\hline
\end{tabular}

Table 13. Specialist Score and Membership of Risk Factor X6

\begin{tabular}{|c|c|c|c|c|c|}
\hline & W & B & G & GD & 0.15 \\
\hline \hline s1 & 0.15 & 0.15 & 0.4 & 0.2 & 0.15 \\
\hline s2 & 0.15 & 0.15 & 0.25 & 0.25 & 0.25 \\
\hline s3 & 0.1 & 0.1 & 0.35 & 0.2 & 0.2 \\
\hline s4 & 0.15 & 0.3 & 0.3 & 0.1 \\
\hline s5 & 0.2 & 0.2 & 0.3349 & 0.201 & 0.1324 \\
\hline M1 & 0.1429 & 0.1889 & 0.32 & 0.2 & 0.15 \\
\hline
\end{tabular}

Table 14. Specialist Score and Membership of Risk Factor X7

\begin{tabular}{|c|c|c|c|c|c|}
\hline & W & B & G & GD & 0.1 \\
\hline \hline s1 & 0.2 & 0.2 & 0.15 & 0.2 & 0.35 \\
\hline s2 & 0.1 & 0.2 & 0.1 & 0.2 & 0.4 \\
\hline s3 & 0.2 & 0.2 & 0.2 & 0.25 & 0.2 \\
\hline s4 & 0.15 & 0.15 & 0.25 & & 0.2 \\
\hline
\end{tabular}


Table 14. contd...

\begin{tabular}{|c|c|c|c|c|c|c|}
\hline & W & B & GE & 0.2 & 0.2 \\
\hline \hline s5 & 0.3 & 0.1 & 0.2 & 0.1440 & 0.3343 \\
\hline M1 & 0.167 & 0.1783 & 0.18 & 0.19 \\
\hline M2 & 0.19 & 0.17 & 0.27 & 0 \\
\hline
\end{tabular}

Table 15. Specialist Score and Membership of Risk Factor X8

\begin{tabular}{|c|c|c|c|c|c|}
\hline & W & B & G & GD & 0.2 \\
\hline \hline s1 & 0.15 & 0.2 & 0.3 & 0.2 & 0.15 \\
\hline s2 & 0.25 & 0.25 & 0.2 & 0.3 & 0.1 \\
\hline s3 & 0.15 & 0.1 & 0.35 & 0.2 & 0.1 \\
\hline s4 & 0.15 & 0.2 & 0.3 & 0.15 \\
\hline s5 & 0.2 & 0.1 & 0.3085 & 0.2451 & 0.129 \\
\hline M1 & 0.1727 & 0.1445 & 0.29 & 0.22 & 0.14 \\
\hline
\end{tabular}

Table 16. Specialist Score and Membership of Risk Factor X9

\begin{tabular}{|c|c|c|c|c|c|}
\hline & W & B & G & 0.1 & 0.1 \\
\hline \hline s1 & 0.5 & 0.2 & 0.1 & 0.2 \\
\hline s2 & 0.35 & 0.25 & 0.1 & 0.1 \\
\hline s3 & 0.6 & 0.1 & 0.1 & 0.2 \\
\hline s4 & 0.45 & 0.1 & 0.1 & 0.1 \\
\hline s5 & 0.3 & 0.2 & 0.2 & 0.1221 \\
\hline M1 & 0.4995 & 0.1461 & 0.12 & 0.1383 \\
\hline M2 & 0.44 & 0.17 & 0.11 & 0.11 \\
\hline
\end{tabular}

Table 17. Specialist Score and Membership of Risk Factor X10

\begin{tabular}{|c|c|c|c|c|c|}
\hline & W & B & G & GD & 0.1 \\
\hline \hline s1 & 0.1 & 0.2 & 0.2 & 0.2 & 0.4 \\
\hline s2 & 0.1 & 0.2 & 0.2 & 0.15 & 0.3 \\
\hline s3 & 0.1 & 0.1 & 0.15 & 0.25 \\
\hline s4 & 0.2 & 0.2 & 0.3 & 0.2 & 0.25 \\
\hline s5 & 0.1 & 0.15 & 0.1823 & 0.1559 & 0.4038 \\
\hline M1 & 0.108 & 0.15 & 0.19 & 0.18 & 0.34 \\
\hline
\end{tabular}


Table 18. Specialist Score and Membership of Risk Factor X11

\begin{tabular}{|c|c|c|c|c|c|}
\hline & W & B & G & GD & 0.1 \\
\hline \hline s1 & 0.2 & 0.4 & 0.2 & 0.2 & 0.1 \\
\hline s2 & 0.1 & 0.2 & 0.2 & 0.15 & 0.2 \\
\hline s3 & 0.25 & 0.25 & 0.1 & 0.2 & 0.3 \\
\hline s4 & 0.2 & 0.2 & 0.2 & 0.1462 & 0.12 \\
\hline s5 & 0.25 & 0.15 & 0.1769 & 0.17 & 0.22 \\
\hline M1 & 0.1881 & 0.3009 & 0.17 & 0.1879 \\
\hline
\end{tabular}

Table 19. Specialist Score and Membership of Risk Factor X12

\begin{tabular}{|c|c|c|c|c|c|}
\hline & W & B & G & GD & 0.5 \\
\hline \hline s1 & 0.05 & 0.05 & 0.2 & 0.2 & 0.2 \\
\hline s2 & 0.1 & 0.2 & 0.2 & 0.4 & 0.3 \\
\hline s3 & 0.1 & 0.1 & 0.15 & 0.45 & 0.3 \\
\hline s4 & 0.05 & 0.1 & 0.1 & 0.45 & 0.1 \\
\hline s5 & 0.1 & 0.1 & 0.1378 & 0.45 \\
\hline M1 & 0.0747 & 0.0909 & 0.15 & 0.43 \\
\hline
\end{tabular}

Table 20. Specialist Score and Membership of Risk Factor X13

\begin{tabular}{|c|c|c|c|c|c|}
\hline & W & B & G & GD & 0.6 \\
\hline \hline s1 & 0.05 & 0.05 & 0.2 & 0.2 & 0.1 \\
\hline s2 & 0.2 & 0.2 & 0.2 & 0.5 & 0.2 \\
\hline s3 & 0.1 & 0.1 & 0.05 & 0.15 & 0.65 \\
\hline s4 & 0.05 & 0.15 & 0.1 & 0.25742 & 0.1 \\
\hline s5 & 0.1 & 0.05 & 0.1277 & 0.1459 \\
\hline M1 & 0.0773 & 0.0749 & 0.14 & 0.17 \\
\hline
\end{tabular}

Table 21. Specialist Score and Membership of Risk Factor X14

\begin{tabular}{|c|c|c|c|c|c|}
\hline & W & B & G & GD & 0.4 \\
\hline \hline s1 & 0.05 & 0.15 & 0.2 & 0.35 & 0.2 \\
\hline s2 & 0.1 & 0.1 & 0.2 & 0.5 & 0.25 \\
\hline s3 & 0.1 & 0.1 & 0.05 & 0.55 & 0.25 \\
\hline s4 & 0.05 & 0.15 & 0.05 & 0.55 & 0.2 \\
\hline
\end{tabular}


Table 21. contd...

\begin{tabular}{|c|c|c|c|c|}
\hline & W & B & G & GD \\
\hline \hline M1 & 0.0794 & 0.1073 & 0.0952 & 0.5021 \\
\hline M2 & 0.08 & 0.11 & 0.12 & 0.216 \\
\hline
\end{tabular}

Table 22. Degree of the Membership of the 14 Risk Factors is Listed Considering the Information Entropy (M1) and the Average Method (M2) in Table 22

\begin{tabular}{|c|c|c|c|c|c|c|c|c|c|c|c|}
\hline \multicolumn{9}{|c|}{ M1 } & \multicolumn{3}{c|}{ M2 } \\
\hline Risk Factor & W & B & G & GD & BE & W & B & G & GD & BE \\
\hline \hline 1 & 0.0839 & 0.1953 & 0.3992 & 0.2501 & 0.0715 & 0.11 & 0.19 & 0.34 & 0.24 & 0.12 \\
\hline 2 & 0.1706 & 0.2299 & 0.2145 & 0.2180 & 0.1671 & 0.19 & 0.18 & 0.22 & 0.22 & 0.19 \\
\hline 3 & 0.2594 & 0.1889 & 0.1985 & 0.2391 & 0.1140 & 0.24 & 0.19 & 0.20 & 0.24 & 0.13 \\
\hline 4 & 0.1391 & 0.2614 & 0.3176 & 0.1764 & 0.1056 & 0.16 & 0.23 & 0.28 & 0.20 & 0.13 \\
\hline 5 & 0.5285 & 0.1419 & 0.1371 & 0.0963 & 0.0963 & 0.47 & 0.16 & 0.13 & 0.12 & 0.12 \\
\hline 6 & 0.1429 & 0.1889 & 0.3349 & 0.201 & 0.1324 & 0.15 & 0.18 & 0.32 & 0.2 & 0.15 \\
\hline 7 & 0.167 & 0.1783 & 0.1440 & 0.1764 & 0.3343 & 0.19 & 0.17 & 0.18 & 0.19 & 0.27 \\
\hline 8 & 0.1727 & 0.1445 & 0.3085 & 0.2451 & 0.1291 & 0.18 & 0.17 & 0.29 & 0.22 & 0.14 \\
\hline 9 & 0.4995 & 0.1461 & 0.1221 & 0.1383 & 0.0941 & 0.44 & 0.17 & 0.12 & 0.16 & 0.11 \\
\hline 10 & 0.108 & 0.15 & 0.1823 & 0.1559 & 0.4038 & 0.12 & 0.17 & 0.19 & 0.18 & 0.34 \\
\hline 11 & 0.1881 & 0.3009 & 0.1769 & 0.1462 & 0.1879 & 0.20 & 0.24 & 0.17 & 0.17 & 0.22 \\
\hline 12 & 0.0747 & 0.0909 & 0.1378 & 0.4945 & 0.2021 & 0.08 & 0.11 & 0.15 & 0.43 & 0.23 \\
\hline 13 & 0.0773 & 0.0749 & 0.1277 & 0.5742 & 0.1459 & 0.10 & 0.11 & 0.14 & 0.48 & 0.17 \\
\hline 14 & 0.0794 & 0.1073 & 0.0952 & 0.5021 & 0.216 & 0.08 & 0.11 & 0.12 & 0.47 & 0.22 \\
\hline
\end{tabular}

$w_{A_{3}}=[0.2738,0.4524,0.2738]^{T}$

$w_{A_{4}}=[0.2738,0.2738,0.4524]^{T}$

\subsubsection{Determination of Evaluation Set}

Evaluation set $\mathrm{V}=\{$ better, good, general, bad, worse $\}$ are listed in Table 7.

\subsubsection{Determine Fuzzy Comprehensive Evaluation}

According to evaluation set, five specialists s1, s2, s3, s4, and s5 score the risk factor X1-X14 and calculate the end result using the information entropy method (M1) and the average values method (M2), five specialists score and member of factor X1-X14 are shown in Table 8-21.

Therefore, degree of the membership of the 14 risk factors is listed in Table $\mathbf{2 2}$ using the information entropy (M1) and the average method (M2).

\subsubsection{Fuzzy Comprehensive Evaluation}

The fuzzy evaluation is calculated in descending to ascending order on the hierarchy and the results of the comprehensive evaluation are obtained. A weighted average of the model operator "." is used in this paper. Comprehensive evaluation matrix is calculated using the degree of membership calculated by information entropy method as follows.

$B_{1}=w_{A_{1}}^{T} \cdot R_{1}=w_{A_{1}}^{T} \cdot\left[\begin{array}{lll}x_{1} & x_{2} & x_{3}\end{array}\right]^{T}=\left(\begin{array}{lll}0.1606 & 0.2096 & 0.2727\end{array}\right.$

$0.23320 .1239)$

$B_{2}=w_{A_{2}}^{T} \cdot R_{2}=w_{A_{2}}^{T} \cdot\left[\begin{array}{lllll}x_{4} & x_{5} & x_{6} & x_{7} & x_{8}\end{array}\right]^{T}=\left(\begin{array}{lll}0.2464 & 0.1767\end{array}\right.$

$0.2478 \quad 0.1786 \quad 0.1507)$

$B_{3}=w_{A_{3}}^{T} \cdot R_{3}=w_{A_{3}}^{T} \cdot\left[\begin{array}{lll}x_{9} & x_{10} & x_{11}\end{array}\right]^{T}=\left(\begin{array}{ll}0.2371 & 0.1902\end{array}\right.$

$\left.\begin{array}{lll}0.1644 & 0.1484 & 0.2599\end{array}\right)$

$B_{4}=w_{A_{4}}^{T} \cdot R_{4}=w_{A_{4}}^{T} \cdot\left[\begin{array}{lll}x_{12} & x_{13} & x_{14}\end{array}\right]^{T}=\left(\begin{array}{lll}0.0775 & 0.0939\end{array}\right.$

$0.1158 \quad 0.5198 \quad 0.1930)$

$B=w_{0}^{T} \bullet R=w_{0}^{T} \bullet\left[\begin{array}{l}B_{1} \\ B_{2} \\ B_{3} \\ B_{4}\end{array}\right]=\left(\begin{array}{llll}0.1946 & 0.1675 & 0.1992\end{array}\right.$

$0.2517 \quad 0.1869)$ 
Comprehensive evaluation matrix are calculated using the degree of membership calculated by average method $\left(\begin{array}{lll}0.1947 & 0.1680 .1976 & 0.24740 .1923\end{array}\right)$.

\subsubsection{Calculation of the Result of Fuzzy Comprehensive Evaluation}

According to corresponding value of the level of risk and the normalized results, rate of risk of information system is calculated as follows.

Total $=0.1946 * 5+0.1675 * 4+0.1992 * 3+0.2517 * 2+0.18$ $69 * 1=2.9312$

Rate of risk of information system using average values method is 2.9255 .

Rate of risk of information system is nearly 3 , value-atrisk is general and the result is consistent with the center of network security situation.

\subsection{Case Analysis}

\subsubsection{Conclusion Analysis}

Using average values method and entropy method to calculate the expert weight, the level of risk factor of system is found to be the same. It means that few lower level of expert cannot affect level of risk of the entire system. However, few low levels of expertise among specialist will affect the result of a single risk factor when using average values method and entropy method, for example, risk factor X5. Information entropy can reflect the degree of dispersion of the risk factor; therefore, when considering the risk profile of individual risk factors, the information entropy method more truly reflects the risk profile of the risk factor than the average method.

\subsubsection{Advantage of Method}

RAMCI is tested in practice; its main advantage is reflected in the following three aspects:

(1) Priority relation matrix transformed into consistent matrix avoid the consistency test of the in the literature [1].

(2) Using the analytic hierarchy process, in accordance with the requirements of ISO / IEC 27002 standard, information systems risk factors were decomposed, it is the universal significance of the information system of risk assessment, to avoid the limitations of the method in the literature [12].

(3) Using the information entropy to calculate the weight of expert ratings is suitable for overall assessment of the information system, and more suitable for considering the risk profile of individual risk factors.

\section{CONCLUSION}

To solve the following problems of information security risk assessment method: inconsistency of judgment matrix, and irrationality of expert weight, RAMCI is proposed, which uses the priority relationship matrix between risk factors to establish a consistent judgment matrix and information entropy to calculate the weight of multiple experts with an indicator score. In comparison with previous assessment methods, RAMCI has the following advantages: it does not bother about the consistency of judgment matrix and objectively reflects the risk profile of individual indicators. So RAMCI is a practical information system risk assessment method.

\section{CONFLICT OF INTEREST}

The authors confirm that this article content has no conflicts of interest.

\section{ACKNOWLEDGEMENTS}

Declared none.

\section{REFERENCES}

[1] F. Dengguo, Z. Yang and Z.Yuqing, "Survey of information security risk assessment", Journal of China Institute of Communications, vol. 25, no.7, pp.10-18, 2004.

[2] Z. Li, Y. Yizhan and P. Jianfen, "Intelligent information security risk assessment based on decision tree algorithm", Journal of Tsinghua University(Science and Technology), vol. 51, no. 10, pp.1236-1239, 2011.

[3] T.L. Satty, "The Analytic Hierarchy Process", New York, USA: McGraw-Hill Companies, 1980

[4] S. Xiaoli, Y.U Jing and S. Haichuan, "The application of fuzzy synthesis evaluation in risk evaluation", Microcomputer Information, vol. 22, no. 12-3, pp. 71-73, 2006.

[5] D.M Zhao, C.G Wang and J.F Ma, "A risk assessment method of the wireless network security", Journal of Electronic, vol. 24, no.3, pp. 428-433, 2007.

[6] W. Xinzhou, "Fuzzy spatial information processing", Wuhan: Wuhan University Press, pp.130 -131, 2003.

[7] Z. Jijun, "Fuzzy analytic hierarchy process (FAHP)", Fuzzy Systems and Mathematics, vol. 14, no. 2, pp. 80-88, 2000.

[8] Y. Min and Z. Sen, "Fuzzy consistent matrix and its application in decision making", Systems Engineering Theory and Practice, pp.78-81, 1998.

[9] C.E Shannon, "A mathematical theory of communication", The Bell System Technical Journal, vol. 27, pp. 379-423, 1948.

[10] E.T. Jaynes, "Information theory and statistical mechanics", Physical Review, vol. 106, no.5, pp. 620-630, 1957.

[11] L. Jing, "Method of fuzzy comprehensive evaluation researched and applied in the field of information security risk assessment", China University of Geosciences 2010.

[12] Z. Dongmei, S. Hongshun and W. Min, "Fuzzy risk assessment of the wireless network security based on entropy theory", Computer Applications and Software, vol. 23, no. 8, pp. 24-26, 2006.

(C) Jianfen and Heng; Licensee Bentham Open.

This is an open access article licensed under the terms of the Creative Commons Attribution Non-Commercial License (http://creativecommons.org/licenses/by-nc/3.0/) which permits unrestricted, non-commercial use, distribution and reproduction in any medium, provided the work is properly cited. 